\title{
Médiévales
}

Langues, Textes, Histoire

54 | printemps 2008

Frères et sœurs

\section{Gli Angiò nell'Italia nord-occidentale (1259-1382), éd. R. COMBA, Milan, Unicopli, 2006, 443 p.}

\section{Simone Balossino}

\section{OpenEdition}

Journals

Édition électronique

URL : https://journals.openedition.org/medievales/5203

DOI : $10.4000 /$ medievales.5203

ISSN : $1777-5892$

\section{Éditeur}

Presses universitaires de Vincennes

\section{Édition imprimée}

Date de publication : 1 juin 2008

Pagination : 153-155

ISBN : $978-2-84292-217-7$

ISSN : 0751-2708

\section{Référence électronique}

Simone Balossino, « Gli Angiò nell'Italia nord-occidentale (1259-1382), éd. R. сомва, Milan, Unicopli, 2006 443 p. », Médiévales [En ligne], 54 I printemps 2008, mis en ligne le 23 octobre 2008, consulté le 23 avril 2022. URL : http://journals.openedition.org/medievales/5203 ; DOI : https://doi.org/10.4000/

medievales.5203

\section{Ce document a été généré automatiquement le 23 avril 2022}

Tous droits réservés 


\title{
Gli Angiò nell'Italia nord-occidentale (1259-1382), éd. R. comBA, Milan, Unicopli, 2006, 443 p.
}

\author{
Simone Balossino
}

1 L'étude de la domination angevine dans les régions de l'Italie du Nord a toujours été un sujet plutôt négligé par l'historiographie italienne, si l'on exclut les quelques études datant des premières décennies $\mathrm{du} \mathrm{xx}^{\mathrm{e}}$ siècle ciblées principalement sur les aspects diplomatiques et militaires (comme par exemple la monographie de Giovanni Maria Monti, La dominazione angioina in Piemonte, Turin, 1939). Le livre Gli Angiò nell'Italia nordoccidentale (1259-1382) édité en septembre 2006 par l'équipe de recherche de l'Université de Milan coordonnée par Rinaldo Comba, avec l'aide de plusieurs spécialistes d'histoire politique et sociale de l'Italie septentrionale et centrale, comble cette lacune. Les résultats auxquels les différentes contributions ici réunies sont parvenus enrichissent considérablement la connaissance que nous avons de la politique angevine dans les régions septentrionales de l'Italie. De plus, ce volume ouvre une série non négligeable de perspectives pour des recherches futures. C'est la conséquence, aussi bien d'une réinterprétation des catégories traditionnelles avec lesquelles l'expérience angevine à été jusqu'à aujourd'hui évaluée, que d'une réadaptation des problématiques historiographiques à l'aide d'approches méthodologiques nouvelles.

2 L'une des idées souvent rappelée tout au long du livre est l'existence d'un véritable projet politique autour duquel la domination angevine, à partir de l'arrivée de Charles $I^{\text {er }}$ (1259) jusqu'à Robert d'Anjou (1346), a pu imprimer un caractère propre au développement des pouvoirs territoriaux italiens. De façon particulière, les groupes sociaux urbains ont su utiliser le dessein politique mis en place par les princes angevins comme un véritable outil de construction institutionnelle. Soutenue par une robuste base idéologique et de propagande, la référence à ce nouveau pouvoir a permis une élaboration originale des configurations institutionnelles, urbaines et seigneuriales, une circulation plus intense du personnel politique entre la Provence et l'Italie du Nord 
et une réflexion inédite, promue par les élites dirigeantes, autour de la culture et des langages politiques.

3 Les thèmes abordés se concentrent autour de trois grandes sections. Dans un premier temps les auteurs s'interrogent sur les formes et les résultats de la domination angevine sur le plan plus proprement institutionnel (Aspetti istituzionali, p. 31-206). Il est intéressant de remarquer comment l'arrivée de princes angevins aboutit à des résultats différents selon les époques et les aires géographiques. Cela s'explique principalement par la variété des pouvoirs territoriaux auxquels la maison d'Anjou a dû s'affronter. Dans la région piémontaise, par exemple, les Angevins dès leur arrivée, créèrent un comté de Piémont (Contea di Piemonte), à cause de la faible résistance rencontré par les nouveaux conquérants à l'intérieur des espaces urbains. Pour ce qui concerne les villes lombardes les princes durent, au contraire, se confronter à des institutions qui avaient de fortes et anciennes traditions d'autonomie communale et qui étaient donc capables d'opposer une véritable résistance à une soumission sans recours. Un troisième cas est représenté par le Latium, où les princes angevins changèrent de stratégie, et s'insérèrent dans les cadres des structures institutionnelles présentes. Charles se fit élire sénateur par les boni homines de Rome et Robert reçut la charge de « capitaine général » des terres d'Église des mains de Clément $\mathrm{V}$ et de Jean XXII. Le choix de Charles de se faire élire par le popolo de Rome fut efficace car il permit, grâce aussi à l'impact idéologique de ce geste, la réalisation d'un programme de plus intense coordination entre les différentes forces politiques présentes en Italie, à utiliser notamment contre le pouvoir maintenu par les derniers Hohenstaufen.

4 Cette politique d'intégration ne doit pas toutefois nous faire oublier que des mouvements d'opposition aux Angevins furent omniprésents. Dans l'aire lombarde et piémontaise, l'opposition vint de pouvoirs territoriaux émergents, comme par exemple les Visconti et les marquis de Montferrat. Ces derniers, grâce aussi à la détermination des soldats piémontais infligèrent, en 1345, aux troupes angevines une défaite sévère à Gamenario, près de Chieri.

5 Les principaux interlocuteurs des angevins furent les seigneurs locaux et les communes. C'est pour cette raison que dans la deuxième partie les contributeurs abandonnent les aspects institutionnels et portent leurs analyses sur le personnel politique qui constitua le véritable lien entre les princes et les communautés urbaines (Gruppi dirigenti e personale politico, p. 209-330). Les différents articles s'articulent ici autour du thème, très fécond, de la circulation du personnel politique en fondant leurs approches sur des analyses prosopographiques (chaque contribution est d'ailleurs dotée de très riches annexes). Du Latium aux communes du Piémont subalpin, les résultats confirment largement la thèse selon laquelle la domination angevine en Italie changea considérablement la provenance géographique des recteurs des villes, qui, à partir de ce moment, sont de plus en plus choisis parmi l'aristocratie francoprovençale. De plus, l'insertion dans le circuit des officiers angevins offrait la possibilité aux familles locales d'entreprendre une carrière politique florissante. C'est grâce à cette conjoncture, par exemple, que des nouveaux groupes familiaux connurent une ascension sociale rapide, comme la famille Falletti d'Albe qui, grâce à ses importantes possibilités financières et à son indépendance vis-à-vis des grands seigneurs locaux, tels que les marquis de Montferrat et de Saluces et les comtes de Savoie, obtint une grande série de privilèges en contrepartie de sa collaboration avec la maison angevine. 
6 La troisième partie du volume examine la culture et les langages politiques, en privilégiant principalement l'étude des formes documentaires et des sources littéraires (Ideologia, società e cultura, p. 333-432). L'approche diplomatique permet en effet de réfléchir, une fois de plus, sur les rapports qui s'instaurèrent entre les communes et les nouveaux princes au moment des soumissions. Elle offre des clefs précieuses pour percevoir l'image que les deux institutions souhaitent offrir d'elles-mêmes, par le biais des instrumenta produits. L'originalité des formes documentaires des actes et leurs hétérogénéités, conséquence de la situation politique complexe, ne cache pas les enjeux qui sont à la base des soumissions: au-delà du plan purement idéologique, nous sommes frappés surtout par la portée des rapports de force qui émergent abondamment des dispositions insérées à l'intérieur des traités.

7 Pour conclure, cet ouvrage constitue donc une étape considérable, non seulement dans l'appréciation de la domination angevine de l'Italie du Nord, mais aussi dans l'histoire de l'Italie des XIII et XIV ${ }^{e}$ siècles tout entière. Comme le rappelle Andrea Zorzi dans les conclusions du volume, méconnaître l'influence des Angevins sur les mécanismes de recomposition territoriale de ces siècles, c'est aussi continuer à réduire l'histoire de l'Italie des $\mathrm{XII}^{\mathrm{e}}-\mathrm{XV}^{\mathrm{e}}$ siècles, aux seuls " développements communaux " d'un côté et aux « expériences seigneuriales » de l'autre qui, trop souvent, contraignent et simplifient la perception des espaces politiques et des constructions institutionnelles médiévales. 